\title{
ПРЕДЛОЖЕНИЯ ПО СОСТАВЛЕНИЮ ДЕФОРМАЦИОННОГО ПАСПОРТА ОБЪЕКТА НЕДВИЖИМОСТИ
}

\section{Евгений Ильич Аврунев}

Сибирский государственный университет геосистем и технологий, 630108, Россия, г. Новосибирск, ул. Плахотного, 10, кандидат технических наук, директор Института кадастра и природопользования, тел. (383)344-31-73, e-mail: kadastr204@yandex.ru

\section{Анастасия Андреевна Бакулина}

Сибирский государственный университет геосистем и технологий, 630108, Россия, г. Новосибирск, ул. Плахотного, 10, обучающийся, тел. (952)905-79-75, e-mail: nastybak-1998@mail.ru

В статье предложена форма деформационного паспорта на объект капитального строительства, для которого необходимо проведение деформационного мониторинга. По аналогии с техническим или межевым планом, деформационный паспорт предлагается формировать из двух частей: аналитической и графической. В аналитической части предлагается помещать информацию, полученную в результате математической обработки результатов геодезических измерений и заключение о возможности безопасного функционирования контролируемого объекта. В графической части отображены данные о месте расположения контролируемого объекта недвижимости и расположение деформационных марок, заложенных в его теле.

Ключевые слова: объект недвижимости, деформационный мониторинг, объект капитального строительства, деформационный паспорт, отметки, деформационные марки, относительные осадки, абсолютные осадки

\section{PROPOSALS FOR REAL ESTATE PREPARATION OF A DEFORMATION PASSPORT}

\section{Evgeny I. Avrunev}

Siberian State University of Geosystems and Technologies, 10, Plakhotnogo St., Novosibirsk, 630108, Russia, Ph. D., Director of the Institute of Cadastre and Environmental Management, phone: (383)344-31-73, e-mail: kadastr204@yandex.ru

\section{Anastasia A. Bakulina}

Siberian State University of Geosystems and Technologies, 10, Plakhotnogo St., Novosibirsk, 630108, Russia, Student, phone: (952)905-79-75, e-mail: nastybak-1998@mail.ru

The article proposes the form of a deformation passport for the capital construction facility, for which deformation monitoring is required. Similar to the technical or inter-plan, the deformation passport should consist of two parts: analytical and graphic. In the analytical part it is proposed to place the information obtained as a result of mathematical processing of geodesic measurements and the conclusion that the controlled object can function safely. The graphical part shows the location of the controlled property and the location of the deformation marks in its body.

Keywords: real estate, deformation monitoring, capital construction object, deformation passport, marks, deformation marks, relative precipitation, absolute precipitation

Все объекты капитального строительства (ОКС), которые расположены в территориальном образовании (ТО), подвержены осадкам и деформациям, вызванным различными тектоническими, антропогенными и техногенными 
факторами. При условии превышения предельно допустимых значений деформации ОКС способствуют появлению различных негативных последствий, вплоть до разрушения сооружений или зданий [1].

Проведение деформационного мониторинга и на основании его результатов заключение о возможности безопасного функционирования инженерного сооружения или здания - является актуальным направлением для соответствующего ТО. В настоящее время участились случаи появления деформаций у ОКС, в связи с этим появилась необходимость в наблюдении за их развитием, для того, чтобы своевременно принять необходимые профилактические меры по их устранению или поддержания контролируемого объекта. Поэтому необходимо проведение деформационного мониторинга, а также разработка сопутствующих документов [2].

Важным аспектом данного направления являются объекты недвижимости $(\mathrm{OH})$, которые подвержены значительным осадкам и соответственно деформациям, теряют свои технические характеристики, следовательно, необходимо пересмотреть их кадастровую стоимость, которая влияет на создание научно-обоснованной и социально справедливой налогооблагаемой базы.

Отмеченные выше факторы обуславливают создание деформационного паспорта на каждый объект капитального строительства. В данном документе должны быть зафиксированы возможные деформации инженерного сооружения, а также заключение о его техническом состоянии. Деформационный паспорт должен являться официальным документом, а его параметры должны закрепляться и обозначаться в нормативно-правовых документах, определяющих выполнение кадастровых и градостроительных работ.

В техническом плане должны быть отражены основные параметры деформационного паспорта. Технический план подготавливается кадастровым инженером для внесения сведений об ОКС в единый государственный реестр недвижимости (ЕГРН) и постановки данного объекта на государственный кадастровый учет (ГКУ). Кроме этого после ввода ОКС в эксплуатацию, деформационный паспорт должен быть передан в управляющую компанию.

Исходя из вышеизложенного, нами предлагается следующая форма деформационного паспорта, которая может включать в себя следующие документы: общие сведения об ОН; данные об исходной высотной основе; каталог отметок деформационных марок, которые заложены в силовые элементы исследуемого ОН (стены, фундамент здания или сооружения); заключение о деформационном состоянии $\mathrm{OH}$.

Предложенная структура деформационного паспорта была разработана на ОКС, расположенный в городе Новосибирск. Предлагаемая форма деформационного паспорта заполняется на основании результатов шести циклов геодезических измерений, выполненных в 2020 году ООО «ГеоСити».

Аналитическая часть деформационного паспорта основана на результатах математической обработки геодезических измерений в шести циклах, представлена в табл. 1-4. 
Основания для проведения деформационного мониторинга объектов капитального строительства

\begin{tabular}{|c|c|}
\hline \multicolumn{2}{|c|}{ ДЕФОРМАЦИОННЫЙ ПАСПОРТ } \\
\hline \multicolumn{2}{|c|}{ Общие сведения об объекте недвижимости } \\
\hline $\begin{array}{l}1 \text { Сведения о заказчике ра- } \\
\text { бот: }\end{array}$ & $\begin{array}{l}\text { ООО «Авангард», генеральный директор Гончаров } \\
\text { Виктор Анатольевич }\end{array}$ \\
\hline $\begin{array}{l}2 \text { Сведения об исполнителе } \\
\text { работ: }\end{array}$ & $\begin{array}{l}\text { Сокращенное наименование юридического лица: } \\
\text { ООО «ГеоСити» } \\
\text { Контактный телефон: (383)233-33-37 } \\
\text { Почтовый адрес: г. Новосибирск, улица Горская, } 2 \\
\text { Электронный адрес: geo@gmail.ru }\end{array}$ \\
\hline 3 Сведения об объекте: & $\begin{array}{l}\text { Адрес (местоположение) объекта: г. Новосибирск, } \\
\text { Октябрьский район, ул. Выборная } \\
\text { Назначение объекта: жилой здание }\end{array}$ \\
\hline \multicolumn{2}{|c|}{ Общие сведения об объекте недвижимости } \\
\hline 4 Сведения об объекте: & $\begin{array}{l}\text { Количество этажей: } 16 \\
\text { Год ввода в эксплуатацию: } 2020\end{array}$ \\
\hline 5 Сведения об измерениях: & $\begin{array}{l}\text { Геометрическое нивелирование I класса. Измерения } \\
\text { выполняются: } \\
\text { 1. На этапе строительства объекта недвижимости. } \\
\text { 2. На этапе строительства объекта недвижимости } \\
\text { и в связи с развитием недопустимых деформаций. } \\
\text { 3. В связи с развитием недопустимых деформаций. }\end{array}$ \\
\hline
\end{tabular}

Таблица 2

Сведения об исходной высотной основе

\begin{tabular}{|c|c|c|c|c|c|c|c|c|c|c|c|c|c|}
\hline \multirow{3}{*}{$\begin{array}{l}\text { Цикл } \\
\text { Дата }\end{array}$} & \multicolumn{7}{|c|}{ Отметки исходных стенных реперов (м) } & \multirow{2}{*}{\multicolumn{6}{|c|}{$\begin{array}{l}\text { Перемещения реперов между } \\
\text { циклами наблюдений (мм) }\end{array}$}} \\
\hline & \multirow{2}{*}{\begin{tabular}{|l|}
0 \\
16.04
\end{tabular}} & \multirow{2}{*}{ I 29.04} & \multirow{2}{*}{$\begin{array}{l}\text { II } \\
12.05\end{array}$} & \multirow{2}{*}{\begin{tabular}{|l|} 
III \\
09.06
\end{tabular}} & \multirow{2}{*}{\begin{tabular}{|l|} 
IV \\
18.07
\end{tabular}} & \multirow{2}{*}{$\begin{array}{l}\mathrm{V} \\
13.09\end{array}$} & \multirow{2}{*}{$\begin{array}{l}\text { VI } \\
12.10\end{array}$} & & & & & & \\
\hline & & & & & & & & $0-\mathrm{I}$ & I-II & I-III & I-IV & $\mathrm{I}-\mathrm{V}$ & $\mathrm{I}-\mathrm{VI}$ \\
\hline 1 & 2 & 3 & 4 & 5 & 6 & 7 & 8 & 9 & 10 & 11 & 12 & 13 & 14 \\
\hline Рп1 & $\begin{array}{l}50,00 \\
0\end{array}$ & 50,000 & 50,000 & 50,000 & 50,000 & 50,000 & 50,000 & 0,0 & 0,0 & 0,0 & 0,0 & 0,0 & 0,0 \\
\hline Рп2 & $\begin{array}{l}49,96 \\
12\end{array}$ & $\begin{array}{l}49,961 \\
0\end{array}$ & $\begin{array}{l}49,961 \\
6\end{array}$ & $\begin{array}{l}49,961 \\
1\end{array}$ & $\begin{array}{l}49,961 \\
0\end{array}$ & 49,9612 & $\begin{array}{l}49,961 \\
1\end{array}$ & $-0,2$ & 0,4 & $-0,1$ & $-0,2$ & 0,0 & $-0,1$ \\
\hline Рп3 & $\begin{array}{l}49,84 \\
41\end{array}$ & $\begin{array}{l}49,844 \\
0\end{array}$ & $\begin{array}{l}49,844 \\
3\end{array}$ & $\begin{array}{l}49,843 \\
9\end{array}$ & $\begin{array}{l}49,844 \\
1\end{array}$ & 49,8440 & $\begin{array}{l}49,843 \\
9\end{array}$ & $-0,1$ & 0,2 & $-0,3$ & $-0,0$ & 0,1 & $-0,1$ \\
\hline 2 Све & дения & средст & вах изм & P & $\begin{array}{l}\text { Цифр } \\
\text { Инва] }\end{array}$ & 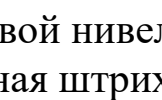 & $P=$ & ro & & xe & 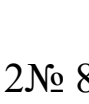 & & \\
\hline
\end{tabular}


Таблицуа 3

Результаты математической обработки геодезических измерений на контролируемом объекте недвижимости

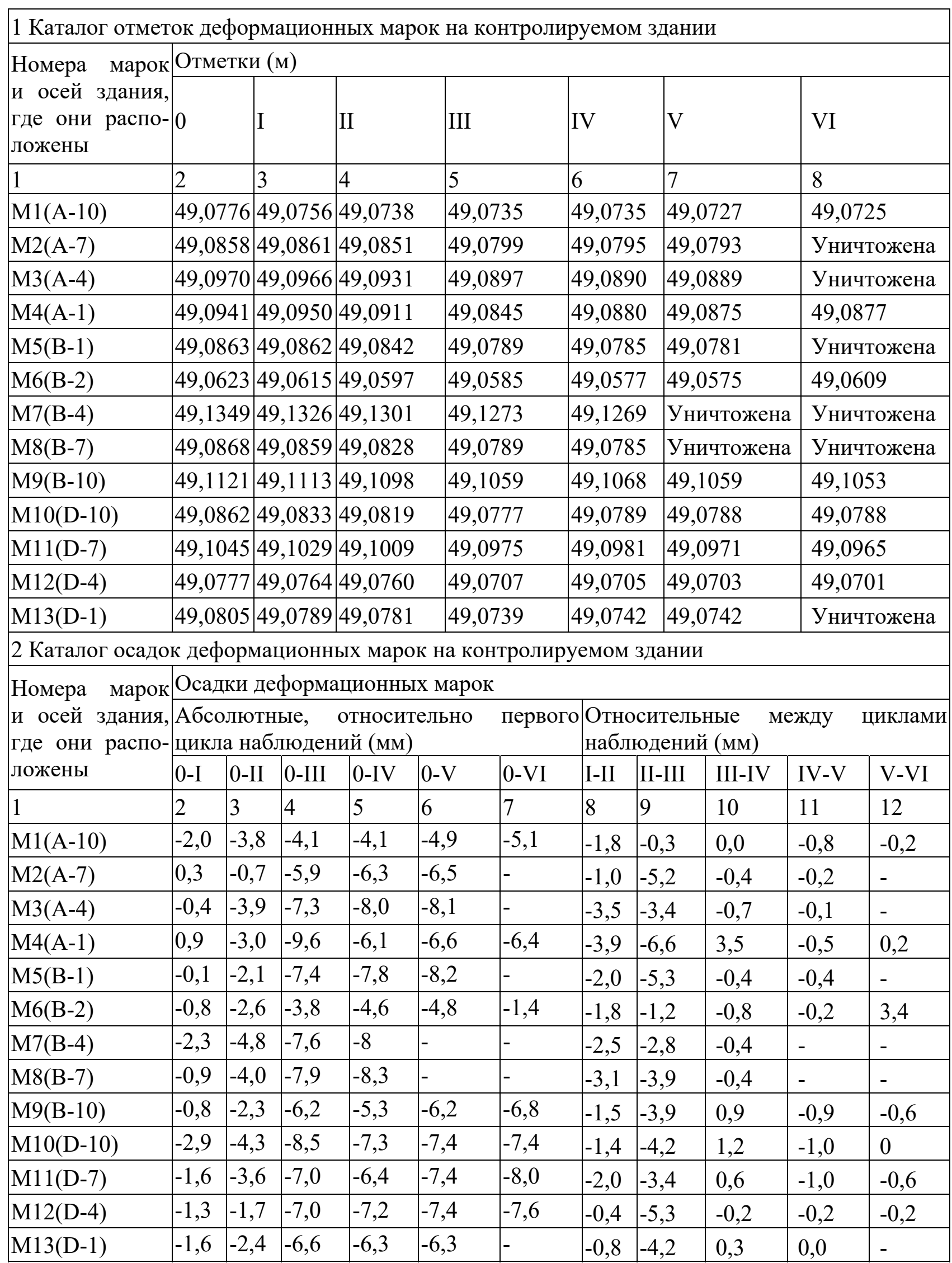


Заключение о деформационном состоянии объекта недвижимости

\begin{tabular}{|c|c|c|}
\hline № & Название параметра & Анализ параметра \\
\hline 1 & Геодезические измерения & $\begin{array}{l}\text { Выполненное высокоточное геометрическое } \\
\text { нивелирование соответствует требованиям } \\
\text { нормативных документов. } \\
\text { Результаты высокоточного геометрического } \\
\text { нивелирования, выполненного по программе } \\
\text { I класса короткими лучами, могут быть ис- } \\
\text { пользованы для создания исходной основы } \\
\text { и надежного определения осадок и деформа- } \\
\text { ций контролируемого объекта недвижимости }\end{array}$ \\
\hline 2 & $\begin{array}{l}\text { Результаты математиче- } \\
\text { ской обработки выполнен- } \\
\text { ных геодезических наблю- } \\
\text { дений }\end{array}$ & $\begin{array}{l}\text { В результате вычисления абсолютных } \\
\text { и относительных осадок деформационных ма- } \\
\text { рок, определено, что контролируемое здание } \\
\text { сохраняет свою стабильность в пространстве } \\
\text { и его перемещение не превышает установлен- } \\
\text { ные нормативные требования }\end{array}$ \\
\hline 3 & $\begin{array}{l}\text { Перемещения в простран- } \\
\text { стве деформационных зна- } \\
\text { ков и определение уровня } \\
\text { их значимости }\end{array}$ & $\begin{array}{l}\text { Все установленные перемещения находятся } \\
\text { в пределах точности геодезических измерений } \\
\text { и являются не значимыми величинами }\end{array}$ \\
\hline № & Название параметра & Анализ параметра \\
\hline 4 & $\begin{array}{l}\text { Заключение о целесооб- } \\
\text { разности проведения даль- } \\
\text { нейших наблюдений и } \\
\text { возможности безопасного } \\
\text { функционирования объек- } \\
\text { та недвижимости }\end{array}$ & $\begin{array}{l}\text { Так как этап строительства завершен, уста- } \\
\text { новленные относительные и абсолютные } \\
\text { осадки являются не значимыми величинами, } \\
\text { то параметры деформаций считать не целесо- } \\
\text { образно }\end{array}$ \\
\hline
\end{tabular}

Графическую часть деформационного паспорта составляют табл. 5 и 6 . Расположение исследуемого объекта представлено в табл. 5.

Исходной основой для составления деформационного паспорт объекта капитального строительства является пространственное определение местоположения деформационных марок в соответствующем цикле геодезических измерений и сравнение их между собой через интервал времени $\Delta \mathrm{t}$. В табл. 6 представлено расположение деформационных марок на исследуемом $\mathrm{OH}$. 
Таблийа 5

Расположение контролируемого объекта. Расположение объекта недвижимости

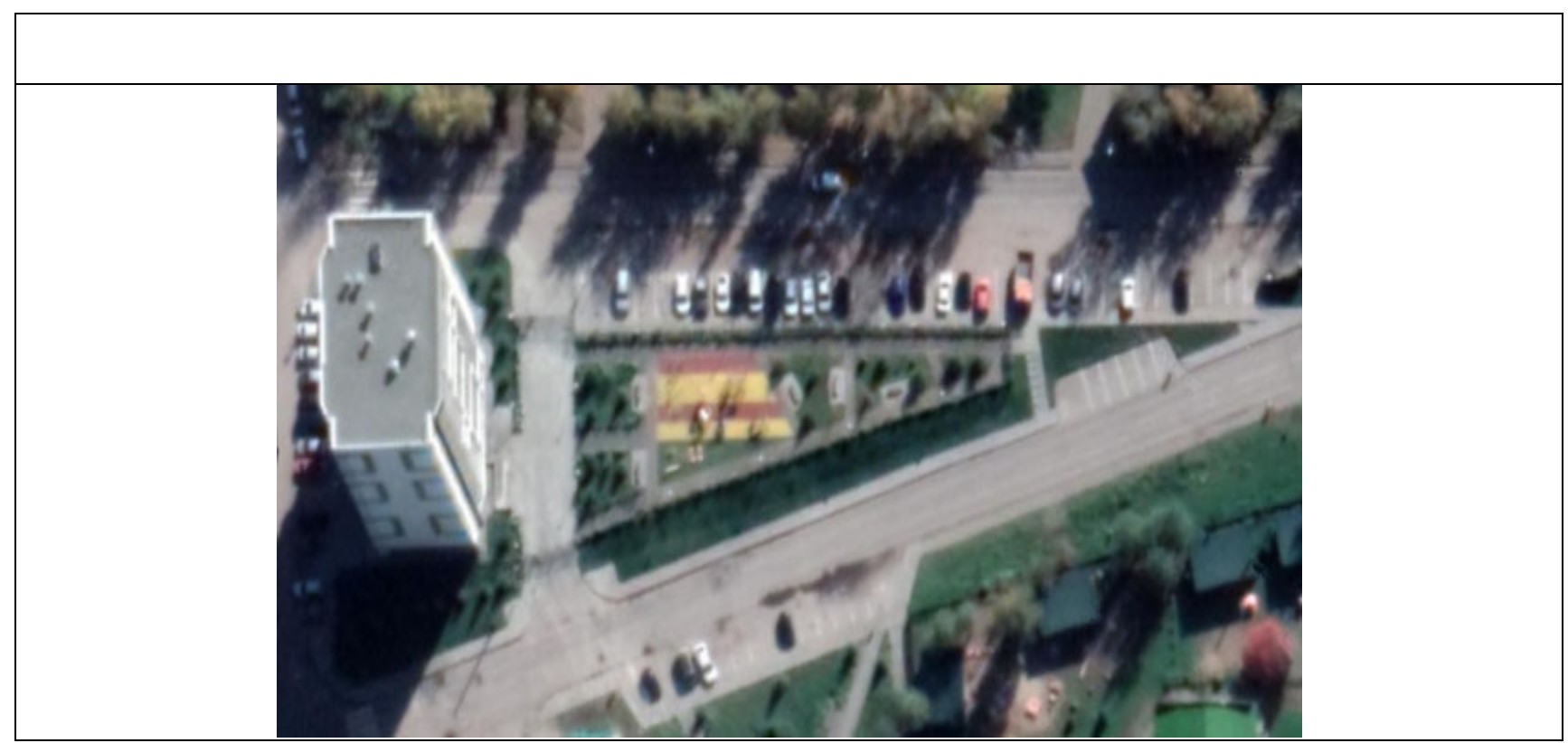

Таблий 6

Расположение деформационных марок на контролируемом объекте. Схема расположения деформационных марок на объекте недвижимости

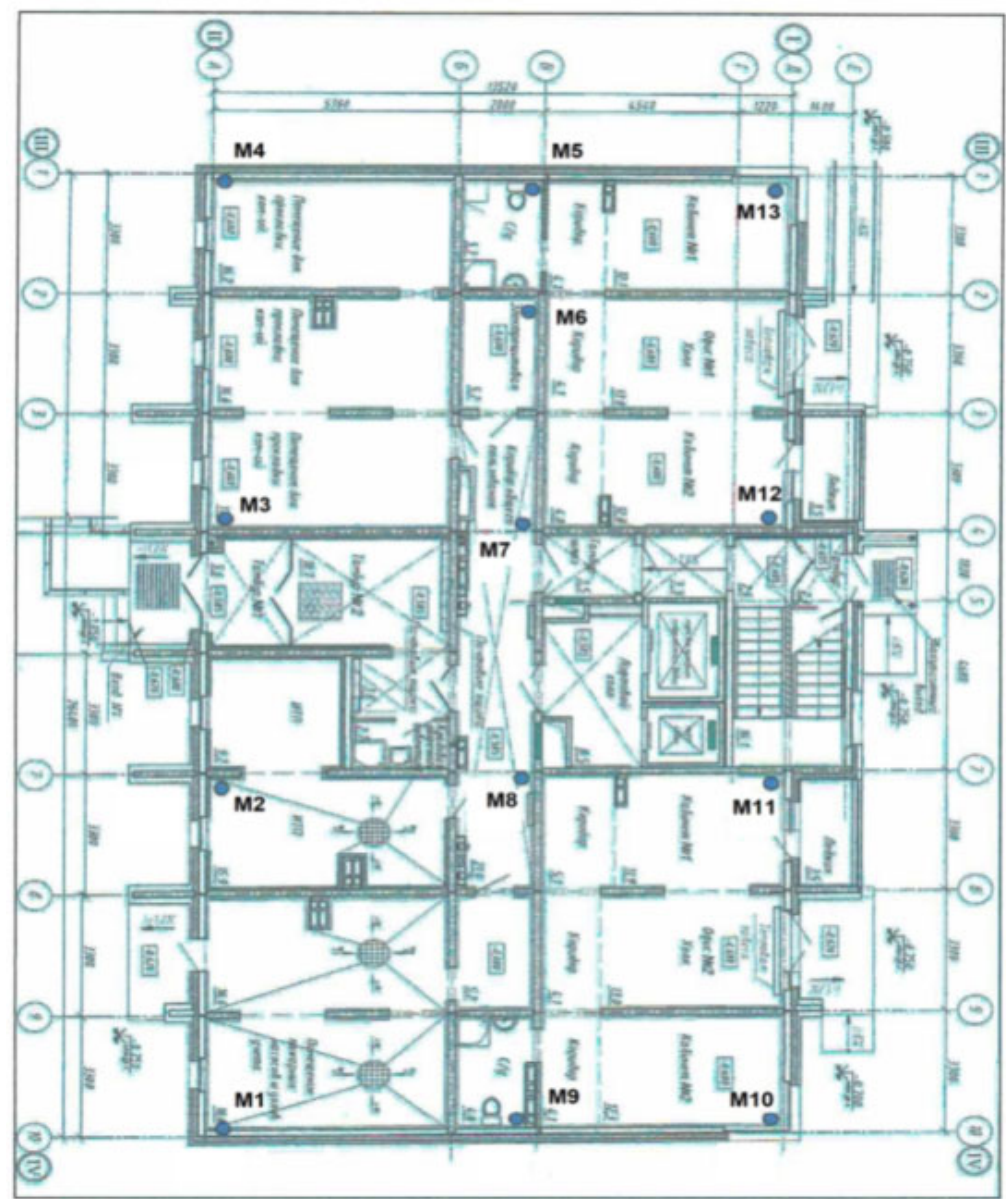


Таким образом, представленный деформационный паспорт может дополнить геопространство ТО достоверной и актуальной информацией о расположенных в нем ОН и, в случае необходимости, позволит запланировать соответствующие профилактические мероприятия по обеспечению безопасного функционирования этого инженерного сооружения.

\section{БИБЛИОГРАФИЧЕСКИЙ СПИСОК}

1. Аврунев Е. И. Геодезическое обеспечение государственного кадастра недвижимости. - Новосибирск: СГГА, 2010.

2. Карпик А. П. Основные принципы формирования геодезического информационного пространства // Известия вузов. Геодезия и аэрофотосъемка. -2013 . - № 4/С. 1. C. $73-78 .-1$.

(C) Е. И. Аврунев, А. А. Бакулина, 2021 